\title{
Estimativa da área foliar de meloeiro em estádios fenológicos por fotos digitais
}

\author{
Estimate of the leaf area of melon plant in growing stages for digital photos
}

\author{
Sidinei José Lopes ${ }^{\mathrm{I}}$ Betânia Brum ${ }^{\mathrm{II}}$ Valdecir José dos Santos ${ }^{\mathrm{II}}$ \\ Evandro Binotto Fagan ${ }^{\text {III }}$ Gean Lopes da Luz ${ }^{\text {III }}$ \\ Sandro Luis Petter Medeiros ${ }^{\mathrm{I}}$
}

\begin{abstract}
O objetivo deste trabalho foi avaliar a precisão do método de fotos digitais na estimativa da área foliar de meloeiro $e$ encontrar modelos matemáticos de estimativa da área foliar em função de medidas lineares da folha para diferentes estádios fenológicos. Foram fotografadas todas as folhas ímpares de 8 plantas após transplante definitivo, através de câmera fotográfica digital, resultando, durante todo o ciclo da cultura, em 4.188 fotos, das quais mediu-se a área foliar, o comprimento e a largura da folha, por meio do software Sigma Scan Pro v. 5.0, Jandel Scientific. Para verificar a precisão do método de fotos digitais, retirou-se uma amostra de 40 folhas, de onde foram obtidas a área foliar através do método padrão de discos foliares e pelo método de fotos. Foi encontrada uma correlação de 0,99 entre o método padrão (discos) e o de fotos. $O$ método de fotos digitais pode ser utilizado para estimar a área foliar da cultura de meloeiro, e a estimativa da área foliar de meloeiro por estádio fenológico apresenta maior precisão, sendo a maior variabilidade na estimativa da área da folha observada no período reprodutivo. A largura máxima da folha de meloeiro é a medida linear que melhor estima a área foliar.
\end{abstract}

Palavras chave: Cucumis melo L., área foliar, método não destrutivo, regressão.

\section{ABSTRACT}

This experiment was aimed at evaluating the precision of digital photos in estimating the leaf area of watermelon plants and to find mathematical models that estimates leaf area as a function of leaf linear measurements at different growth stages. All odd leaves of eight plants were photographed after being established on the field using a digital camera that resulted in 4,188 photos in which length and width were measured using a Sigma Scan Pro v. 5.0 Jandel Scientific software. In order to estimate the precision of the digital photos method, a sample consisting of 40 leaves was taken and leaf area measured using the standard leaf disks and the photo method. A 0.99 correlation coefficient was detected between the two methods. Therefore digital photos can be used to estimate leaf area of watermelon plants and estimation of leaf area per growth stage presents higher precision. The larger variability in leaf area was observed during reproductive growth. Maximum leaf width is the measure that best estimates leaf area.

Key words: Cucumis melo L, leaf area, non destructive method, regression.

A área foliar de meloeiro é uma importante medida para avaliar a eficiência quanto à fotossíntese e, conseqüentemente, a produção final (COSTA, 1999). Sua avaliação durante todo o ciclo da cultura auxilia na modelagem do crescimento e do desenvolvimento da planta e, em conseqüência, na produtividade e na produção total da cultura (TERUEL, 1995).

Entre os métodos existentes para determinação da área foliar, os não destrutivos permitem a repetição das medidas durante o período de crescimento, reduzindo o erro experimental associado a procedimentos amostrais destrutivos (NE SMITH, 1992). O uso de equações de regressão para estimar a área foliar é um método não destrutivo, simples, rápido, preciso e confiável. O procedimento usual deste

IDepartamento de Fitotecnia, Universidade Federal de Santa Maria (UFSM), 97105-900, Santa Maria, RS, Brasil. E-mail: sjlopes@ccr.ufsm.br. Autor para correspondência.

IICurso de Agronomia, UFSM, Santa Maria, RS, Brasil.

IIIPrograma de Pós-graduação em Agronomia, CCR, UFSM, Santa Maria, RS, Brasil. 
método envolve medidas do comprimento, da largura e das áreas de folhas amostradas e, em seguida, a obtenção dos coeficientes de regressão que relacionam as medidas lineares com a área da folha (WIERSMA \& BAILEY, 1975). Apesar das vantagens citadas, este necessita, muitas vezes, de equipamentos, tais como: laser óptico e medidores sofisticados, que dificultam a realização de pesquisas, por torná-las dispendiosas. Outro problema é o formato irregular das bordas da folha de meloeiro, que dificulta a obtenção de medidas com planímetros.

O objetivo do presente trabalho foi avaliar a precisão do método de fotos digitais na estimativa da área foliar de meloeiro e encontrar modelos matemáticos de estimativa da área foliar em função de medidas lineares da folha em diferentes estádios fenológicos.

Foi conduzido um experimento em hidroponia no Departamento de Fitotecnia da Universidade Federal de Santa Maria, com a cultivar de meloeiro (Cucumis melo L.), variedade Cantalupensis, híbrido “Torreon”, de setembro de 2003 a janeiro de 2004.

Considerou-se o ciclo da planta em três estádios: o estádio 1, fase vegetativa até a fixação do primeiro fruto em $50 \%$ das plantas (1ํ dia após transplante (DAT) até o 20ํDAT); o estádio 2, fixação do primeiro fruto em $50 \%$ das plantas até a colheita dos primeiros frutos ( $21^{\circ}$ até $56^{\circ}$ DAT); e o estádio 3 , colheita dos frutos (57ํa até 67ํㅡㄹ DAT). O número de folhas

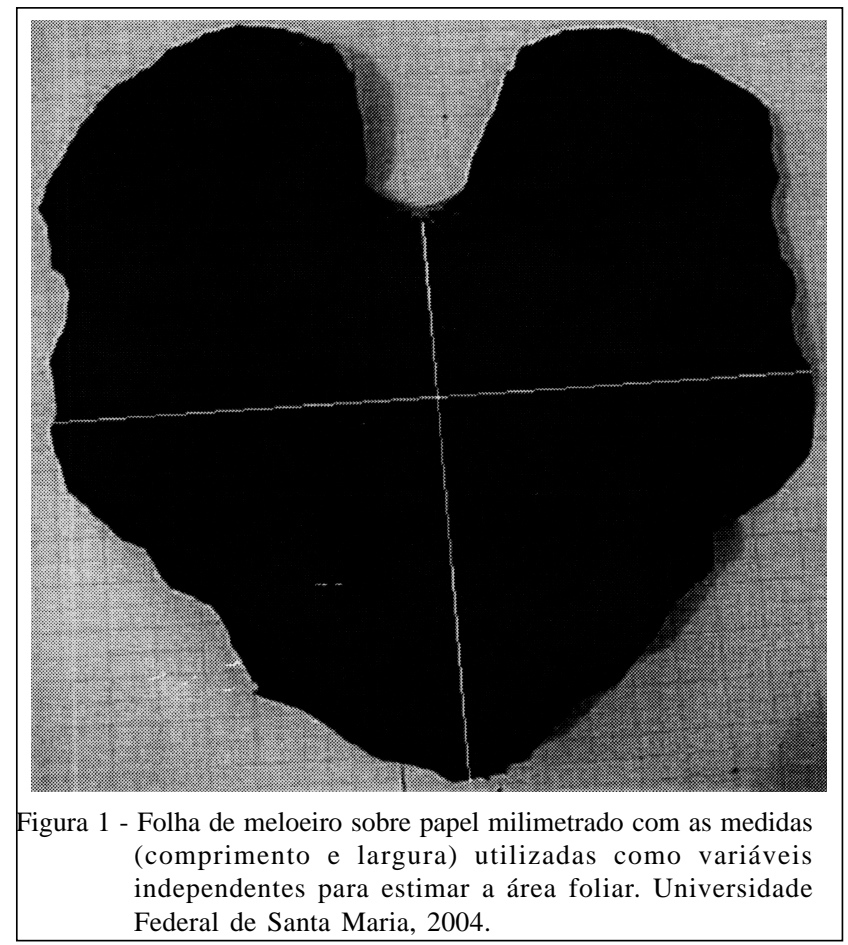

fotografadas e medidas foram de 905, 2.655 e 628, nos estádios 1, 2 e 3, respectivamente, totalizando 4.188 folhas no ciclo completo.

Para avaliação da área foliar, foram fotografadas todas as folhas ímpares de 16 plantas no berçário e de 8 plantas após o transplante para os canais de cultivo definitivos, desde que a folha tivesse no mínimo 5cm de largura. As folhas das plantas foram fotografadas diariamente, entre as sete e nove horas da manhã, através de uma câmera digital da marca Sony série MVC-FD75. Sob as folhas, foi colocada uma folha de papel milimetrado, como referencial de medida das fotos.

As medidas lineares comprimento, largura e área das folhas foram obtidas pelo programa Sigma Scan Pro v. 5.0, Jandel Scientific (Figura 1), processando as fotos digitais das folhas. As equações de regressão para estimar a área foliar, através das variáveis independentes: comprimento da nervura principal (C), largura máxima (Lmáx.) e associação de ambos (C e Lmáx.) foram obtidas no programa Table Curve 2D e 3D(JANDEL SCIENTIFIC, 1991).

Para validação do método de fotos digitais, coletaram-se 40 folhas, que foram fotografadas individualmente, sendo, posteriormente, determinadas as suas áreas foliares pelo método destrutivo de discos foliares (método padrão) e pelo método de fotos. A análise da correlação de Pearson entre os métodos foi realizada pelo software estatístico NTIA/EMBRAPA.

Diante das funções polinomiais ajustadas pelo programa Table Curve, os critérios adotados para escolher as funções que melhor relacionam as medidas lineares com a área foliar foi o menor número de parâmetros destas e o maior coeficiente de determinação, bem como a análise de dispersão de pontos no gráfico.

Para verificar a relação entre as medidas lineares e a área foliar, desconsiderando as folhas menores, foram ajustadas equações, com os mesmos critérios de ajustes anteriormente citados, para a estimativa de área foliar a partir do comprimento e da largura máxima da folha, utilizando-se a exclusão de $25 \%$ das menores folhas do conjunto de dados.

A correlação de Pearson entre as medidas obtidas pelo método padrão, por meio de discos foliares, com as medidas obtidas pelas fotos digitais, foi de 0,99 , sendo vantajosa sua utilização pela rapidez, facilidade e por não constituir um método destrutivo. Em trabalho com nastúrcio (Tropaeolum majus L.), comparando os mesmos métodos, SANTOS et al. (2005) também observaram uma alta correlação $(0,94)$.

Ciência Rural, v.37, n.4, jul-ago, 2007. 
Pelo critério de maior coeficiente de determinação (R2) e dispersão dos pontos no gráfico, obteve-se bom ajuste com equações polinomiais quadráticas, em todos os estádios fenológicos, com a utilização das variáveis independentes: C, Lmáx. e C e Lmáx de folha (cm). Entretanto, o valor do R2 foi menor no estádio 3, em relação aos estádios 1 e 2, em todas as equações avaliadas (Tabela 1 ). A redução do R2 no estádio 3 foi mais pronunciada quando as equações foram ajustadas a partir do comprimento da folha. Tal resultado indica que, no período reprodutivo, o comprimento da folha tem maior variação do que a largura. Portanto, para maior precisão em trabalhos de estimativa de área foliar de meloeiro durante a colheita de frutos, devem-se utilizar medidas da largura máxima de folha.

Este resultado é também um indicativo de que, no período vegetativo, quando os fotoassimilados são deslocados apenas para as folhas, existe menor variabilidade na forma das folhas. No período reprodutivo, observou-se maior variabilidade no tamanho e na forma das folhas, pois o deslocamento dos fotoassimilados para os frutos provocou, além de redução na área das folhas em formação, redução na emissão de folhas novas e a senescência de folhas mais velhas. Ou seja, no período reprodutivo, para maior confiabilidade dos resultados, deve-se aumentar o número de folhas amostradas.

Os maiores valores de R2 e a menor dispersão dos pontos no gráfico ocorreram quando se estimou a área foliar a partir de medidas da largura máxima de folha, em todos os estádios fenológicos e também para o ciclo completo (Tabela 1). Este resultado é similar ao observado por NASCIMENTO et al. (2002), para o melão amarelo, híbrido "Gold Mine”, em que a maior precisão na estimativa da área foliar foi obtida com as medidas de largura em relação às de comprimento de folha, para um modelo potencial. Os autores atribuíram este resultado à inserção do pecíolo no limbo foliar e também ao seu formato cordiforme, que dificulta a medida do comprimento da folha, aumentando-se os erros associados a sua determinação. Além disso, citam que a largura da folha mantém-se mais estável no decorrer do ciclo da cultura de meloeiro.

Em trabalhos com nastúrcio, cujo formato da folha é orbicular (forma mais ou menos circular), ao relacionar medidas de quatro diagonais da folha com as respectivas áreas foliares, obtidas por fotos digitais, foi observado bom ajuste de um modelo exponencial para todas as diagonais (R2 > 0,99) (SANTOS et al., 2005).

Considerando os $75 \%$ dos maiores valores do conjunto de dados, ajustaram-se equações lineares de estimativa de área foliar, que foram: $Y=$ $120,78+27,5951 X(R 2=0,59)$, ajustada para o comprimento; e $Y=-138,97+20,07 X(R 2=0,87)$, para a largura máxima da folha. Verifica-se que, ao se utilizar a largura máxima da folha como variável independente, a precisão da equação é maior, e, nesta situação, o aumento de um centímetro na largura máxima da folha equivale a aproximadamente $20 \mathrm{~cm}$ de área foliar para um conjunto de dados, de onde foram excluídos $25 \%$ das folhas menores, com valor mínimo de largura máxima da folha de aproximadamente $12 \mathrm{~cm}$. Portanto,

Tabela 1 - Equações ajustadas para estimativa de área foliar de meloeiro, através de medidas lineares de comprimento (C), largura (Lmáx) e comprimento versus largura máxima, em três estádios fenológicos. Santa Maria, 2004.

\begin{tabular}{|c|c|c|}
\hline Estádio & Equação ajustada & $\mathrm{R}^{2}$ \\
\hline 1 & $\mathrm{AF}=-14,5163+2,7105 \mathrm{C}^{(1)}+$ 0,6718 Lmáx+ 0,6037Lmáx & 0,96 \\
\hline 2 & AF $=$-16,4964 + 7,2033C- 2,3250 Lmáx + 0,6090 Lmáx & 0,95 \\
\hline 3 & AF = -35,0866 + 7,6225 C - 0,2953 Lmáx + 0,4959 Lmáx & 0,92 \\
\hline Ciclo completo & AF = -17,1774 + 6,0948 C - 1,3163 Lmáx + 0,5890 Lmáx & 0,95 \\
\hline 1 & $\mathrm{AF}=-37,9396+9,3303 \mathrm{C}+1,0182 \mathrm{C}$ & 0,88 \\
\hline 2 & $A F=-20,873+7,323 C+0,9871 C$ & 0,80 \\
\hline 3 & $\mathrm{AF}=73,4729-10,3032 \mathrm{C}+1,6544 \mathrm{C}$ & 0,70 \\
\hline Ciclo completo & $A F=-34,9952+10,8789 C+0,79338 C$ & 0,82 \\
\hline 1 & $\mathrm{AF}=-12,6459$ + 2,4788 Lmáx + 0,5940Lmáx & 0,96 \\
\hline 2 & $\mathrm{AF}=-14.559+$ 3,2810 Lmáx+ 0,5545 Lmáx & 0,94 \\
\hline 3 & $\mathrm{AF}=-6,8645+$ 2,9671 Lmáx + 0,5171 Lmáx & 0,88 \\
\hline Ciclo completo & $\mathrm{AF}=-16,1882+$ 3,4768 Lmáx + 0,5433 Lmáx & 0,95 \\
\hline
\end{tabular}

Estádio 1: fase vegetativa até a fixação do primeiro fruto em $50 \%$ das plantas ( $1^{\circ}$ dia após transplante (DAT) até o $20^{\circ}$ DAT); Estádio 2 : fixação do primeiro fruto em $50 \%$ das plantas até a colheita dos primeiros frutos $\left(21^{\circ}\right.$ até $56^{\circ}$ DAT); e Estádio 3: colheita dos frutos (57 até $\left.67^{\circ} \mathrm{DAT}\right)$.

Ciência Rural, v.37, n.4, jul-ago, 2007. 
uma estimativa da área foliar aproximada poderá ser realizada com essas relações e com a opção de medições de folhas que apresentem mais que $12 \mathrm{~cm}$ de largura.

O método de fotos digitais pode ser utilizado para estimar a área foliar da cultura de meloeiro, e a estimativa da área foliar de meloeiro por estádio fenológico apresenta maior precisão, sendo a maior variabilidade na estimativa da área da folha observada no período reprodutivo. A largura máxima da folha de meloeiro é a medida linear que melhor estima a área foliar.

\section{REFERÊNCIAS}

COSTA, M.C. Efeitos de diferentes lâminas de água com dois níveis de salinidade na cultura do meloeiro. 1999. 115f. Tese (Doutorado em Agronomia) - Universidade Estadual de São Paulo, Botucatu.

JANDEL SCIENTIFIC. User's manual. California, 1991. 280p.
NASCIMENTO, I.B. et al. Estimativa da área foliar do meloeiro. Horticultura Brasileira, v.20, n.4, p.555-558, 2002.

NE SMITH, D.S. Estimating summer squash leaf area nondestructively. Hort Science, v.27, n.1, p.77, 1992.

SANTOS, J.V. et al. Estimativa da área foliar da falsa alcaparra (Tropaeolum majus L.) sob ambiente protegido e análise de crescimento. In: REUNIÃO ANUAL DA SBPC - Do Sertão Olhando o Mar, Cultura \& Ciência, 57., 2005, Fortaleza, CE. Anais... Fortaleza: Universidade Estadual do Ceará, 2005. 1 CD-ROOM.

TERUEL, D.A. Modelagem do índice de área foliar de cana-de-açúcar em diferentes regimes hídricos. 1995. 93f. Dissertação (Mestrado em Agronomia) - Escola Superior de Agricultura Luiz de Queiroz, Piracicaba.

WIERSMA, J.V.; BAILEY, T.B. Estimation of leaflet, trifoliate, and total leaf area of soybeans. Agronomy Journal, v.67, p.26-30, 1975. 